HADI HATAMI, M.Sc. ${ }^{1}$

E-mail: hadi.hatami.69@gmail.com

IMAN AGHAYAN, Ph.D. ${ }^{1}$

(Corresponding author)

E-mail: iman.aghayan@shahroodut.ac.ir

${ }^{1}$ Department of Civil Engineering,

Shahrood University of Technology

Shahrood, Iran
Traffic Engineering

Original Scientific Paper

Submitted: 23 Jan. 2016

Accepted: 21 Sep. 2016

\title{
TRAFFIC EFFICIENCY EVALUATION OF ELLIPTICAL ROUNDABOUT COMPARED WITH MODERN AND TURBO ROUNDABOUTS CONSIDERING TRAFFIC SIGNAL CONTROL
}

\begin{abstract}
This paper compared the performance of elliptical roundabout with turbo and modern roundabouts. It considers the effects of increasing the central island radius and speed limit on delay and capacity. Three types of roundabouts (modern, turbo and elliptical roundabouts) with different numbers of lanes (single lane, two-lane and three-lane) were designed. Unsignalized and signalized controls were applied for these roundabouts. The robustness of the designed roundabouts was investigated for saturated and unsaturated flow conditions. Based on the obtained results, increasing the central island radius had both positive and negative effects on delay and capacity. However, a positive effect on these variables was observed in all roundabouts when increasing the speed limit. In unsignalized and signalized control under unsaturated flow conditions, a modern roundabout had lower delay time than an elliptical roundabout. Moreover, in saturated flow, the elliptical roundabout had the best performance in terms of delay. Overall, in comparison with the turbo roundabouts, modern and elliptical roundabouts had the highest capacities in unsignalized and signalized controls. This study can provide useful information for engineers who decide to design a roundabout.
\end{abstract}

\section{KEY WORDS}

capacity; delay; elliptical roundabout; modern roundabout; turbo roundabout; traffic signal control;

\section{INTRODUCTION}

Nowadays, a roundabout is a good alternative to an intersection. Roundabouts provide major safety benefits in comparison with conventional signalized intersections. A modern roundabout is slightly different from a conventional roundabout. The difference between a modern and a conventional roundabout is in the right of way. A modern roundabout gives priority to a circulating flow; however, a conventional roundabout gives priority to traffic that enters the roundabout [1]. Fortuijn [2] developed turbo roundabouts in the Netherlands. A turbo roundabout is a circular intersection that separates vehicles in lanes with mountable lane dividers to reduce the conflict points. The turbo roundabout has six fundamental forms: the knee roundabout, the star roundabout, the egg roundabout, the basic turbo roundabout, the spiral roundabout and the rotor roundabout. Another type of roundabouts are elliptical roundabouts used widely in Iran. These roundabouts have an elliptical central island with two different radii. An elliptical roundabout is a good choice when constraints such as right of way, existing roadway alignments, buildings, and/or wetlands influence the shape. A few studies investigated the performance of elliptical roundabout. In addition, previous research has not compared the behaviour of elliptical roundabouts with other roundabouts. Thus, this can be useful for engineers who decide to design a roundabout.

The main objectives of roundabout design are to maximize traffic safety and operational efficiency. Easa and Mehmood [3, 4] developed a model that optimized these objectives. This model was more efficient than the traditional iterative approach. Mauro and Cattani [5] analysed the function and economy of different layouts for choosing the best road intersection. The compact roundabout turned out to be the layout with the least overall cost. In functional, environmental and economic terms, Tollazzi et al. [6] also compared the target roundabout with one- or two-level roundabout intersections. Zhang et al. [7] found that roundabouts with moderate queue length had better performance than the pre-timed traffic signals. In contrast, by increasing the queue length excessively, the pre-timed traffic signals showed better performance. Gagnon and Sadek [8] assessed the calibration potential of common analytical and micro-simulation roundabout models. They found that calibration could have a significant impact on improving the results of the model. Several studies have examined the capacity of roundabouts. Qu et al. [9] estimated the entry capacity of single lane modern roundabout using a case study in Queensland. Sisiopiku and Oh [10] compared the performance of a roundabout with a four-leg 
intersection. They found that the roundabout had higher capacity than a signalized intersection. Al-Madani [11] examined two- and three-lane roundabouts during heavy-demand conditions. He also developed a multivariate model for the prediction of maximum entry flow by considering the circulating flow, exit flow and roundabout geometric characteristics. Yap et al. [12] examined the three main methodologies based on the following models: fully empirical, gap acceptance and simulation software. They found that each of these methodologies on their own could not completely explain the complex behavioural and physical processes involved in roundabout entries due to their limitations. Chang et al. [1] studied the effect of delay reduction by replacing intersections with modern roundabouts. They found that the intersections at which the average traffic volume in entry areas was between 160 and 180 (veh/h/lane, vehicle per hour per lane) had significant effect on delay reduction. In terms of safety, Kim and Choi [13] investigated the crash data of roundabouts to identify major factors of crashes. Then, they developed a model for investigating the relationship between crashes and roundabout geometric characteristics. Some studies investigated the effect of traffic signals on roundabout performance. Tracz and Chodur [14] studied the effect of traffic signals on roundabouts and they arrived to the conclusion that roundabouts with traffic signals performed better in heavy traffic conditions. Bai et al. [15] also determined the main factors that had effect on the maximum capacity in signalized roundabouts. These factors were the number of entry lanes and the radius of the central island. Maher [16] applied the cross-entropy method (CEM) to the problem of signal settings optimization on a signalized roundabout. Maher found that the CEM had the potential to be a useful technique for traffic signal optimization problems.

Silva et al. [17] compared the performance of conventional roundabouts with turbo roundabouts. They found that turbo roundabouts provided more capacity only in very specific scenarios. Mauro and Branco [18] found that, under specific circumstances, turbo roundabouts performed better than roundabouts in terms of capacity and delay. In urban context, turbo roundabouts showed good performance considering simultaneous presence of pedestrians and vehicles $[19,20]$. Giuffrè et al. [21] found that the performance of turbo roundabouts highly depended on traffic situations. Turbo roundabouts performed better on major roads with higher demands. Due to the reduction of conflict points, turbo roundabouts were safer than conventional roundabouts. Hoek [22] investigated two types of turbo roundabouts (rotor and star roundabouts) with regard to the applicability of traffic signals. He calculated the capacity of these turbo roundabouts and found that the signalized turbo roundabout only allowed leg-by-leg control. He also compared these signalized turbo roundabouts with unsignalized control systems and found that signalized rotor roundabout (four-leg) had lower capacity than unsignalized rotor roundabout. The capacity of signalized star roundabout (three-leg) was larger than unsignalized star roundabout; however, signalized star roundabout had longer delay time. Tollazzi et al. [23] introduced a new type of roundabout with depressed lanes for right turning (the flower roundabout). This kind of roundabout combined positive characteristics of the normal and turbo roundabouts. Thus, the performance of flower roundabout was superior to the high percentage of vehicles turning right.

There are two main objectives of this study; the first objective is to investigate the behaviour of elliptical roundabouts and compare it with modern and turbo roundabouts by considering unsignalized control. The second objective is to analyse these roundabouts with regard to signalized control system and compare them with unsignalized control systems. In addition, the effects of radius and speed variations on the roundabout performance are studied. Various models and scenarios were defined in AIMSUN (Advanced Interactive Microscopic Simulator for Urban and Non-urban Networks) to achieve these objectives.

\section{MODEL DEVELOPMENT}

Modelling was carried out according to some assumptions. Based on these assumptions (see Table 1), models were designed in AIMSUN, a simulation software developed by the Spanish TSS Company in 1986. Depending on traffic demand data, two types of simulations are considered in AIMSUN. One of these simulations is based on input traffic flows and the turning percentages. The other one is based on O/D Matrices and paths used in this study. The size of the central island plays a key role in determining the amount of deflection imposed on the through vehicle's path. Also, the entry radius is an important factor in determining the operation of a roundabout as it has significant impacts on both capacity and safety. The entry radius in conjunction with the entry width, the circulatory roadway width, and the central island geometry, controls the amount of deflection imposed on a vehicle's entry path. Moreover, entry radii are related to entry speed. These parameters affect the criteria of safety and driving comfort. In this paper the parameters of roundabout design were considered according to roundabouts constructed in Iran and the Federal Highway Administration (FHWA) Roundabout Guidebook [24].

After designing all of the roundabouts in AIMSUN for both signalized and unsignalized conditions, traffic loads were assigned (see Figure 1). In this study, the actuated traffic control was used in roundabouts. In addition, the right-of-way control was considered for unsignalized roundabouts that were given priority to 
H. Hatami, I. Aghayan: Traffic Efficiency Evaluation of Elliptical Roundabout Compared with Modern and Turbo Roundabouts...

Table 1 - Summary of roundabout designs

\begin{tabular}{||c|c|c|c|c|c|c||}
\hline $\begin{array}{c}\text { Number } \\
\text { of lanes }\end{array}$ & $\begin{array}{c}\text { Types } \\
\text { of roundabouts }\end{array}$ & $\begin{array}{c}\text { Speed } \\
\text { limits }[\mathrm{km} / \mathrm{h}]\end{array}$ & $\begin{array}{c}\text { Central island } \\
\text { radii }[\mathrm{m}]\end{array}$ & $\begin{array}{c}\text { Total traffic } \\
\text { volume }[\mathrm{veh} / \mathrm{h}]\end{array}$ & $\begin{array}{c}\text { Controlling } \\
\text { systems }\end{array}$ & Outputs \\
\hline \hline Single lane & $\begin{array}{c}\text { Modern } \\
\text { and elliptical }\end{array}$ & 25,35 & $15,20,22.5$ & $\begin{array}{c}800,1,200,1,600, \\
2,000,2,400,3,600, \\
4,800\end{array}$ & US* and S* & $\begin{array}{c}\text { Delay and } \\
\text { capacity }\end{array}$ \\
\hline \multirow{2}{*}{ Two lanes } & $\begin{array}{c}\text { Modern, turbo } \\
\text { and elliptical }\end{array}$ & $25,35,40$ & $15,25,35$ & $\begin{array}{c}8,00,1,200,1,600, \\
2,400,3,600, \\
4,800\end{array}$ & US and S & $\begin{array}{c}\text { Delay and } \\
\text { capacity }\end{array}$ \\
\hline \multirow{2}{*}{ Three lanes } & $\begin{array}{c}\text { Modern, turbo } \\
\text { and elliptical }\end{array}$ & $25,35,40$ & $25,45,50$ & $\begin{array}{c}1,200,1,600,2,000, \\
2,400,3,600,4,800, \\
6,000\end{array}$ & US and S & $\begin{array}{c}\text { Delay and } \\
\text { capacity }\end{array}$ \\
\hline
\end{tabular}

*US: Unsignalized, S: Signalized

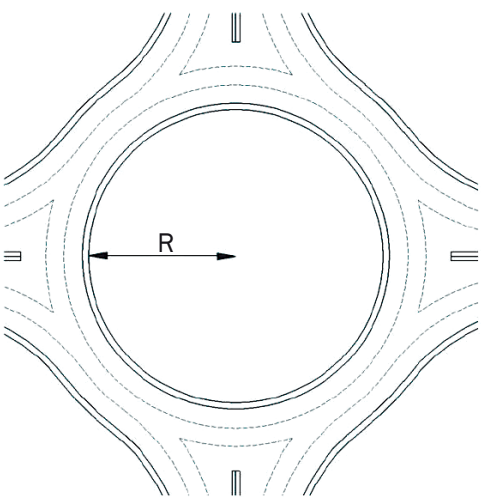

a) Modern roundabout

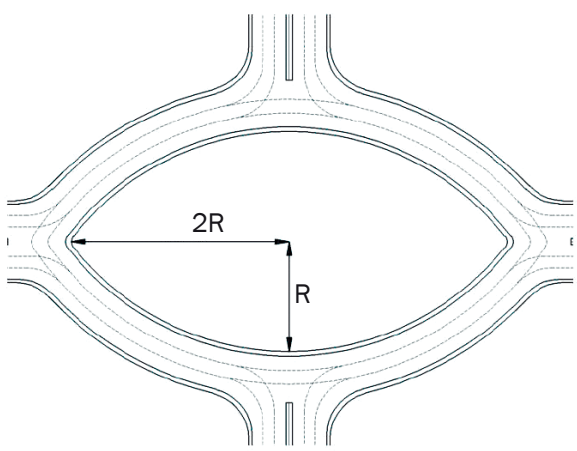

b) Elliptical roundabout

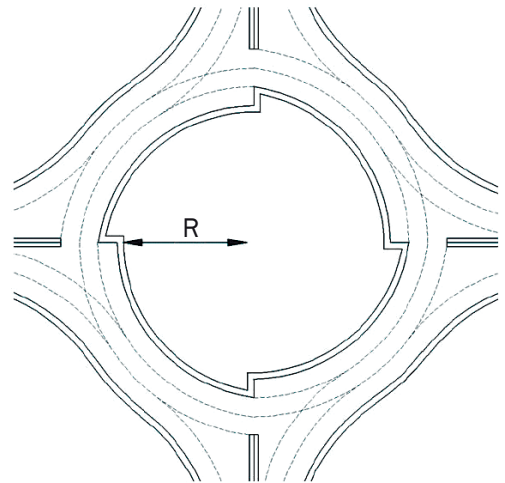

c) Turbo roundabout

Figure 1 - Types of studied roundabouts

circulating flow. This controlling system allowed roundabouts to perform better than uncontrolled systems. Each roundabout was designed in three categories (single lane, two-lane and three-lane roundabouts) except for turbo roundabout (two-lane and threelane roundabouts). Each category has three different speed limits (25, 35 and $40 \mathrm{~km} / \mathrm{h}$ ) for circular roadway except for single lane roundabout (25 and $35 \mathrm{~km} / \mathrm{h}$ ). Moreover, three different central island radii were applied for each category by considering unsignalized and signalized conditions.

The following assumptions were considered for this study:

1) The roundabouts were in urban areas and passenger vehicles were considered as traffic flow.

2) The width of circular lane was 120 percent of the entry lane width [24].

3) The turning movements of vehicles were $30 \%$ right turn, 30\% through, 30\% left turn and 10\% U-turn. These turnings were assigned to all models and traffic volumes.

4) The speed limit of $50 \mathrm{~km} / \mathrm{h}$ was applied to roadways.

5) In a circular roadway, entry radius was defined for each speed limit. For single lane roundabouts, entry radii were 15 and $30 \mathrm{~m}$ allocated to the speed limit of 25 and $35 \mathrm{~km} / \mathrm{h}$; respectively. For two-lane and three-lane roundabouts, entry radii were 15 , 30 and $45 \mathrm{~m}$ allocated to speed limits of 25, 35 and $40 \mathrm{~km} / \mathrm{h}$, respectively. The speed limit of 40 $\mathrm{km} / \mathrm{h}$ was not considered for single lane roundabouts, because the entry radii typically ranged from 15 to $30 \mathrm{~m}$ [24].

6) In elliptical roundabouts, large radius assumed twice the small radius.

7) The type of turbo roundabout used in this research was the rotor roundabout with more capacity.

\section{RESULTS AND DISCUSSION}

The traffic volumes were assigned and each simulation was repeated 10 times in order to obtain better results. The average delay and the capacity of each model were determined. The results were estimated in two different situations. First, by considering the constant speed, the effects of radius variations were studied, and second, by considering the constant radius, the effects of speed variations were studied. The delay time was estimated in unsaturated and saturated flows.

\subsection{Single lane roundabouts}

For a constant speed of $35 \mathrm{~km} / \mathrm{h}$, the effect of radius variations on delay is shown in Figure 2. Figure 3 
depicts the effect of speed changes on delay for a constant radius of $20 \mathrm{~m}$. The results of capacity in two different scenarios are represented in Figure 4.

As seen in Figure 2, by increasing the central island radius, the delay was decreased significantly in signalized roundabouts. Meanwhile, the delay was increased slightly in unsignalized roundabouts. In signalized controlling system under unsaturated flow, modern roundabout had less delay time than elliptical roundabout. However, under saturated flow condition, the behaviour of elliptical roundabout was better than modern roundabout in terms of delay time.
In unsignalized roundabouts under unsaturated and saturated flow, the same behaviour was observed. Overall, in unsignalized and signalized roundabouts, modern roundabout had lower delay time than elliptical roundabout under unsaturated flow conditions; however, in saturated flow elliptical roundabout had the lowest delay time.

The effect of different speed limits on delay time is shown in Figure 3. By increasing the speed limit in circular roadway, delay was decreased in both signalized and unsignalized roundabouts. In signalized controlling system under unsaturated flow, modern

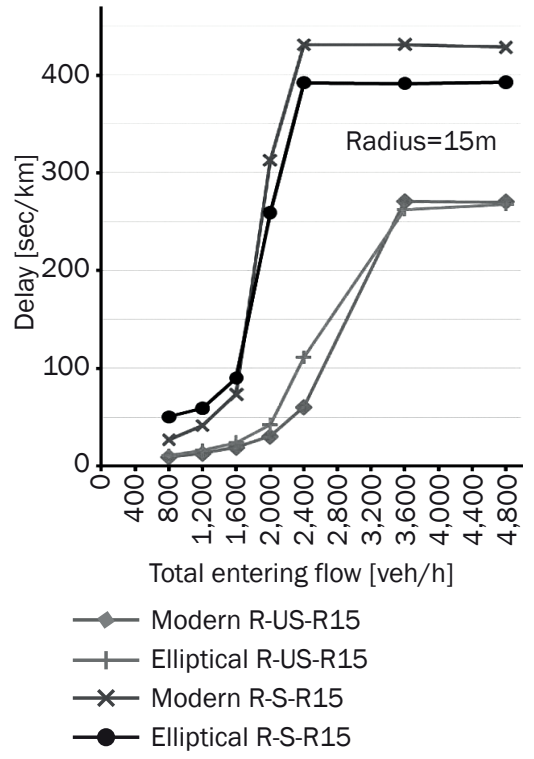

a) Radius of $15 \mathrm{~m}$

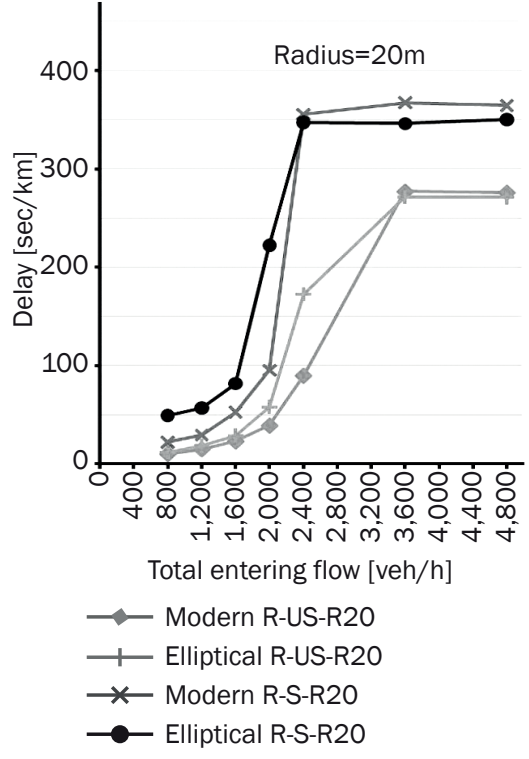

b) Radius of $20 \mathrm{~m}$

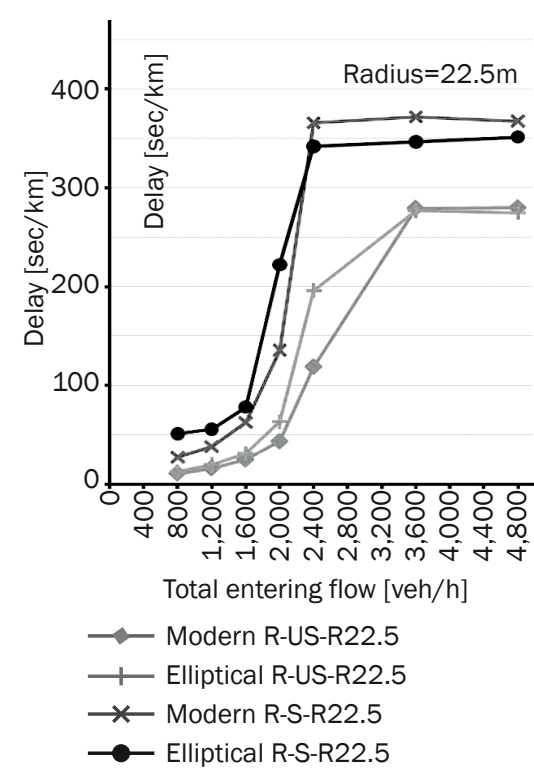

c) Radius of $22.5 \mathrm{~m}$

Figure 2 - The effect of radius variations on delay for a constant speed of $35 \mathrm{~km} / \mathrm{h}$ among different types of single lane roundabouts $(R=$ roundabout, $S=$ signalized, US=unsignalized)

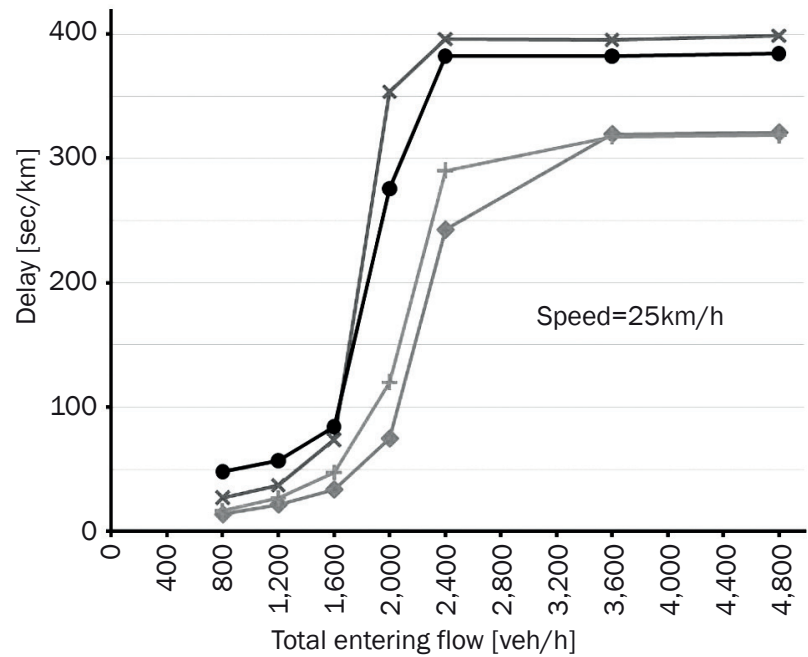

$\begin{array}{ll}\longrightarrow \text { Modern R-US-S25 } & + \text { Elliptical R-US-S25 } \\ \rightarrow \text { Modern R-S-S25 } & \longrightarrow \text { Elliptical R-S-S25 }\end{array}$

a) Speed of $25 \mathrm{~km} / \mathrm{h}$

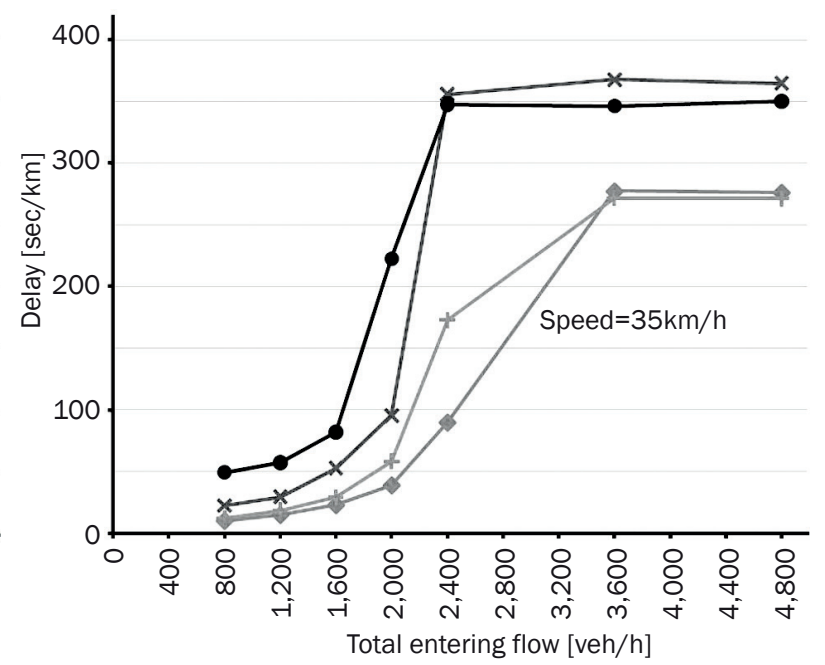

$\begin{array}{ll}\longrightarrow \text { Modern R-US-S35 } & \longrightarrow \text { Elliptical R-US-S35 } \\ x \text { - Modern R-S-S35 } & \longrightarrow \text { Elliptical R-S-S35 }\end{array}$

b) Speed of $35 \mathrm{~km} / \mathrm{h}$

Figure 3 - The effect of speed variations on delay for a constant radius of $20 \mathrm{~m}$ among different types of single lane roundabouts 
roundabout had less delay time than elliptical roundabout. However, under saturated flow condition, the performance of elliptical roundabout was better than modern roundabout. The same behaviour was observed among unsignalized roundabouts under unsaturated and saturated flow conditions.

The results of capacity are depicted in Figure 4 . The capacity of unsignalized roundabouts was larger than in the case of signalized roundabouts. By increasing the central island radius, the capacity of unsignalized roundabouts decreased. However, the capacity of signalized roundabouts was slightly increased (See Figure 4a). By comparing the two types of roundabouts, the modern roundabout had larger capacity than the elliptical roundabout in both unsignalized and signalized controls. By increasing the speed limit in the circular roadway, the capacity of all roundabouts was increased (See Figure 4b). Increasing the central island radius and the speed limit was more effective among unsignalized roundabouts. A summary of the results

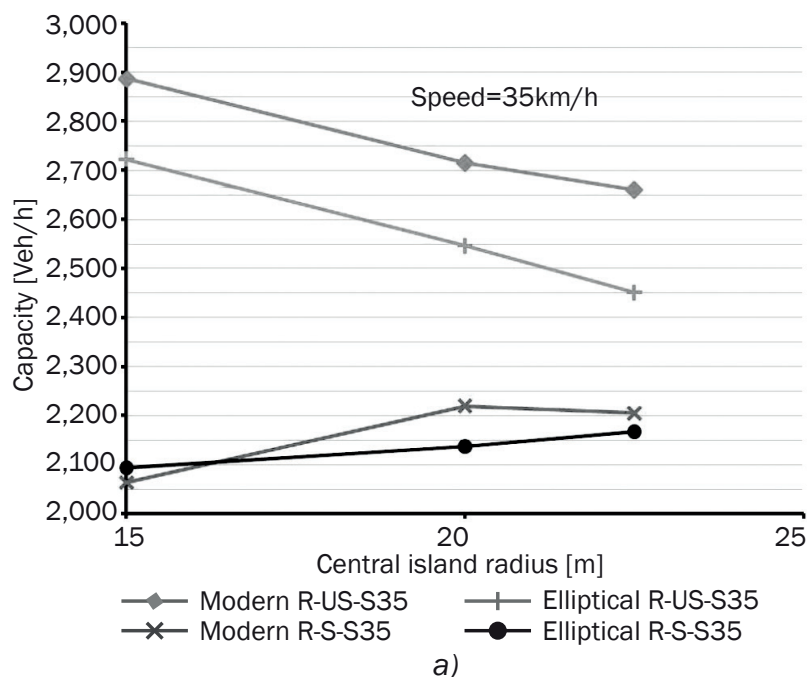

observed for different single lane roundabouts is presented in Table 2.

\subsection{Two-lane roundabouts}

Delay and capacity were calculated based on two scenarios. First, by considering a constant speed of 35 $\mathrm{km} / \mathrm{h}$, the effects of changing the central island radius on delay and capacity were determined. Then, the effect of changing the speed limit for a constant radius of $25 \mathrm{~m}$ was calculated.

Figure 5 shows the effect of radius variations on delay for a constant speed of $35 \mathrm{~km} / \mathrm{h}$. By increasing the radius of unsignalized modern and turbo roundabouts under unsaturated flow condition, first, the delay was slightly increased (in radius of 15 and 25 $\mathrm{m}$ ) and then decreased (in radius of $35 \mathrm{~m}$ ). For unsignalized elliptical roundabout under unsaturated flow condition, an increase in radius had negative impact on delay and caused its increase. In unsignalized control under saturated flow, the delay was decreased

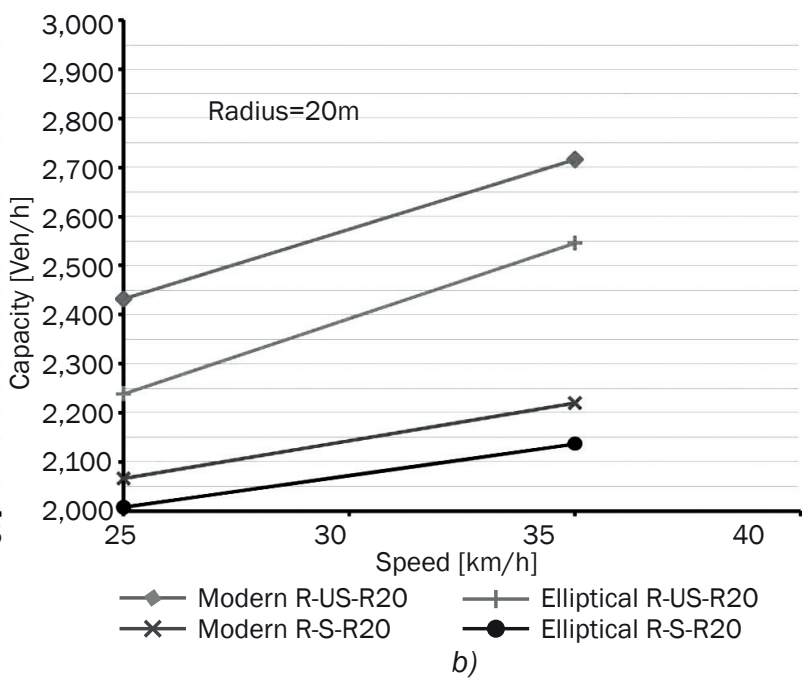

Figure 4 - The effects of radius (a) and speed limit (b) on capacity among different types of single lane roundabouts

Table 2 - Summary of the results observed for different single lane roundabouts

\begin{tabular}{|c|c|c|c|c|c|c|}
\hline & \multicolumn{2}{|c|}{ Modern roundabout } & \multicolumn{2}{|c|}{ Turbo roundabout } & \multicolumn{2}{|c|}{ Elliptical roundabout } \\
\hline & Unsignalized & Signalized & Unsignalized & Signalized & Unsignalized & Signalized \\
\hline \multicolumn{7}{|c|}{ The effect of increasing the radius on delay } \\
\hline Unsaturated flow & $-*$ & $+*$ & N/A & N/A & - & + \\
\hline Saturated flow & - & + & N/A & N/A & - & + \\
\hline \multicolumn{7}{|c|}{ The effect of increasing the speed limit on delay } \\
\hline Unsaturated flow & + & + & N/A & N/A & + & + \\
\hline Saturated flow & + & + & N/A & N/A & + & + \\
\hline \multicolumn{7}{|c|}{ The effect of increasing the radius on capacity } \\
\hline & - & + & $\mathrm{N} / \mathrm{A}$ & $\mathrm{N} / \mathrm{A}$ & - & + \\
\hline \multicolumn{7}{|c|}{ The effect of increasing the speed limit on capacity } \\
\hline & + & + & N/A & $\mathrm{N} / \mathrm{A}$ & + & + \\
\hline
\end{tabular}

* (+): positive effect, (-): negative effect 


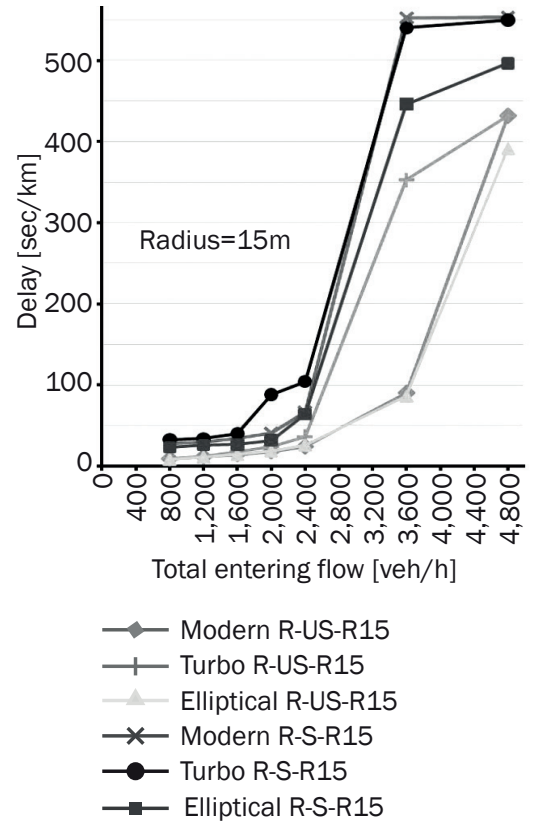

a) Radius of $15 \mathrm{~m}$

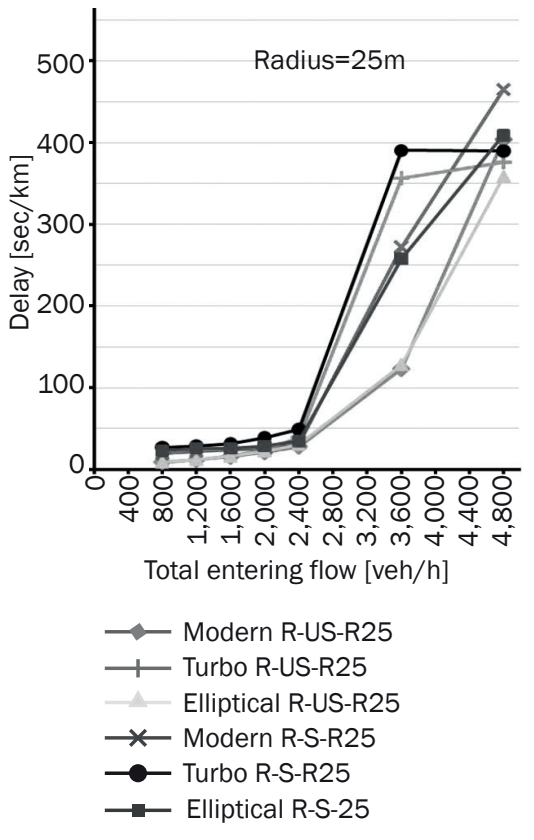

b) Radius of $25 \mathrm{~m}$

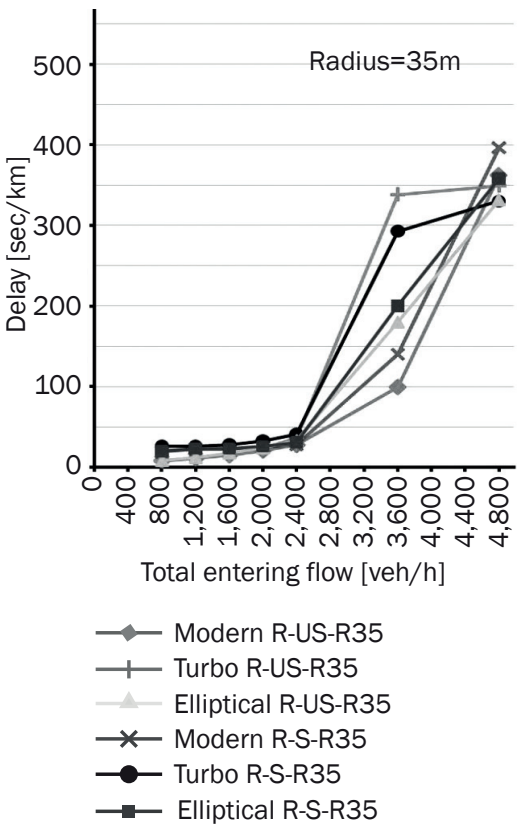

c) Radius of $35 \mathrm{~m}$

Figure 5 - The effect of radius variations on delay for a constant speed of $35 \mathrm{~km} / \mathrm{h}$ among different types of two-lane roundabouts

in all roundabouts. In all of the signalized roundabouts, an increase in radius had a positive impact on delay and caused it to be decreased under unsaturated and saturated flow conditions.

In Figure 5, under unsaturated flow condition, the elliptical roundabout had the lowest delay time among unsignalized roundabouts with radius of 15 and $25 \mathrm{~m}$. However, in radius of $35 \mathrm{~m}$, the modern roundabout had the lowest delay time. In unsignalized roundabouts under saturated flow, the elliptical roundabout had the lowest delay time. Moreover, in signalized roundabouts, the same behaviour was observed. In all flow conditions, unsignalized roundabouts were better in delay than signalized roundabouts except for turbo roundabout with a radius of $35 \mathrm{~m}$.

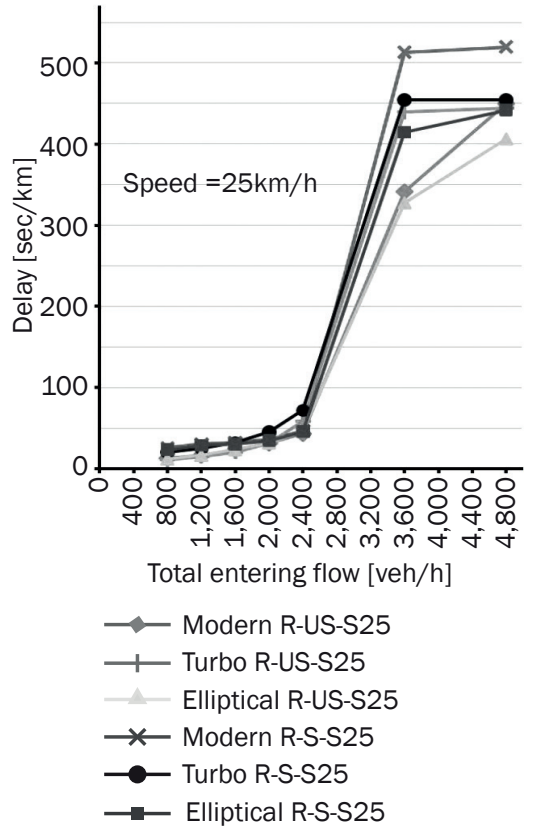

a) Speed of $25 \mathrm{~km} / \mathrm{h}$

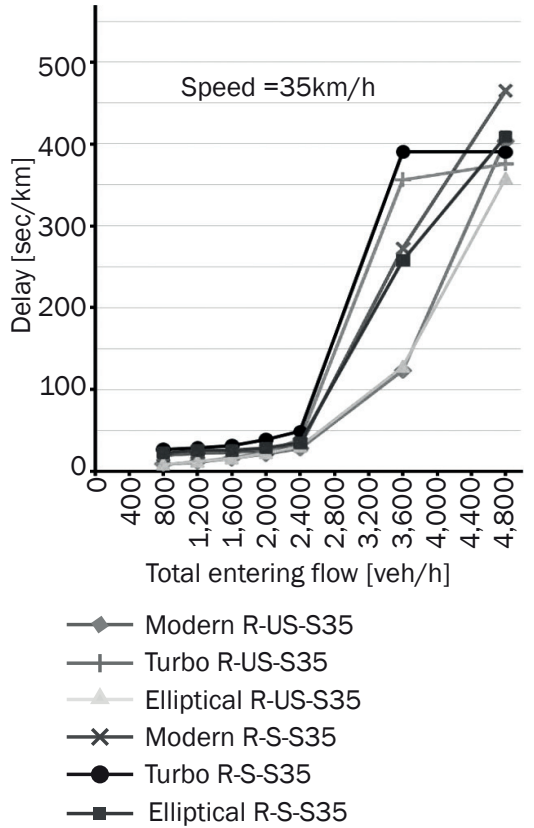

b) Speed of $35 \mathrm{~km} / \mathrm{h}$

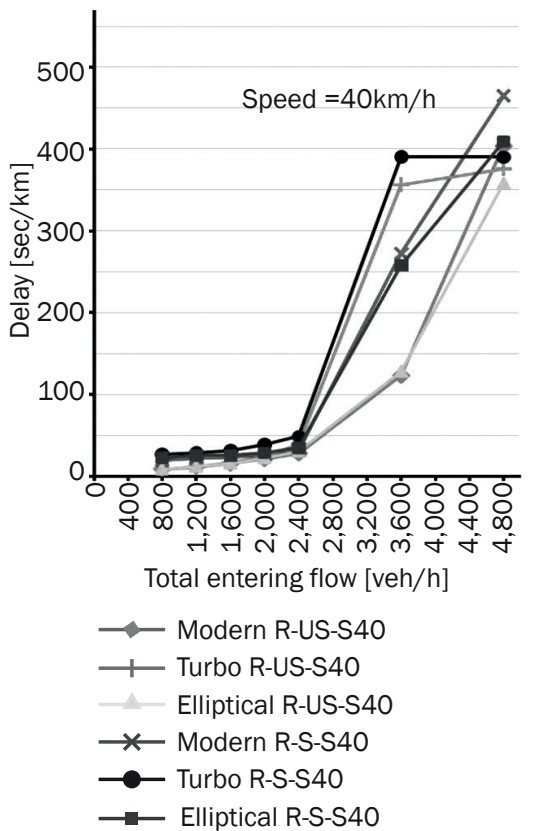

c) Speed of $40 \mathrm{~km} / \mathrm{h}$

Figure 6 - The effect of speed variations on delay for a constant radius of $25 \mathrm{~m}$ among different types of two-lane roundabouts 
In Figure 6, the effect of speed limit variations on delay for a constant radius of $25 \mathrm{~m}$ is depicted. An increase in speed limit caused the delay to be decreased in all roundabouts. In unsignalized roundabouts under unsaturated and saturated flow conditions, respectively, modern and elliptical roundabouts had the lowest delay time in all speed limits. In signalized roundabouts under unsaturated flow, the elliptical roundabout had the lowest delay time in speed limit of 25 and $35 \mathrm{~km} / \mathrm{h}$; however, for speed limit of $40 \mathrm{~km} / \mathrm{h}$, the modern roundabout showed better performance than the other roundabouts. In the saturated flow, the elliptical roundabout had the best performance at speed limit of $25 \mathrm{~km} / \mathrm{h}$. However, for the speed limit of 35 and $40 \mathrm{~km} / \mathrm{h}$, the turbo roundabout had lower delay time than the elliptical roundabout. In all roundabouts under different flow conditions, the unsignalized control was better than the signalized control.

The results of capacity are shown in Figure 7. An increase in radius caused a decrease in the capacity of unsignalized roundabouts (Figure 7a). In signalized

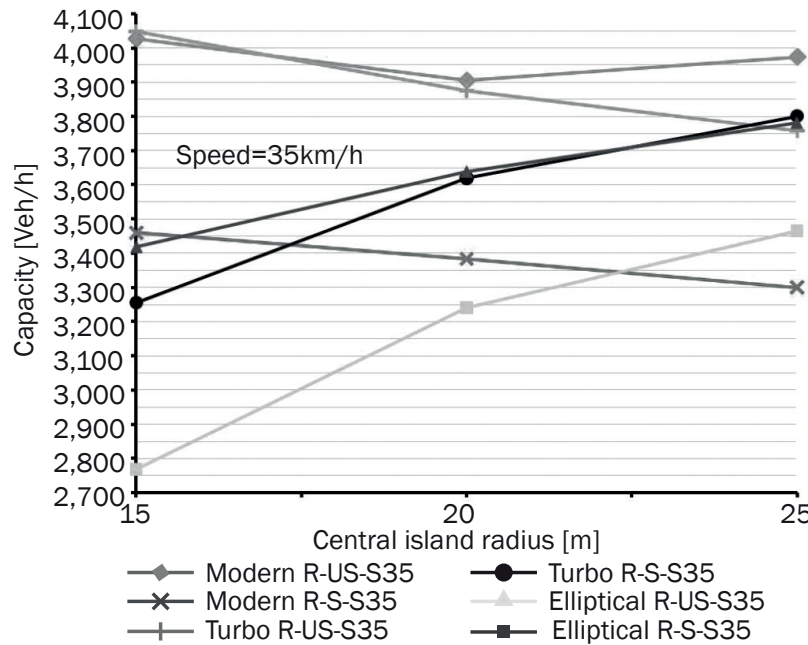

a) roundabouts the capacity was increased by increasing the radius. The capacity of unsignalized roundabouts was larger than of signalized roundabouts. However, by increasing the radius, the signalized elliptical and turbo roundabouts had the best performance in capacity. The largest effect of increasing the central island radius on the capacity was achieved in a signalized turbo roundabout.

The effect of increasing the speed limit on the capacity is represented in Figure $7 \mathrm{~b}$. The effect of an increase in speed limit was almost similar to all roundabouts and caused their capacity to be increased. The signalized and unsignalized turbo roundabouts had the lowest capacity in all roundabouts. In addition, unsignalized modern roundabout had larger capacity than unsignalized elliptical roundabout. However, in signalized roundabouts, the elliptical roundabout provided larger capacity than other roundabouts. A summary of the results observed for different two-lane roundabouts is shown in Table 3.

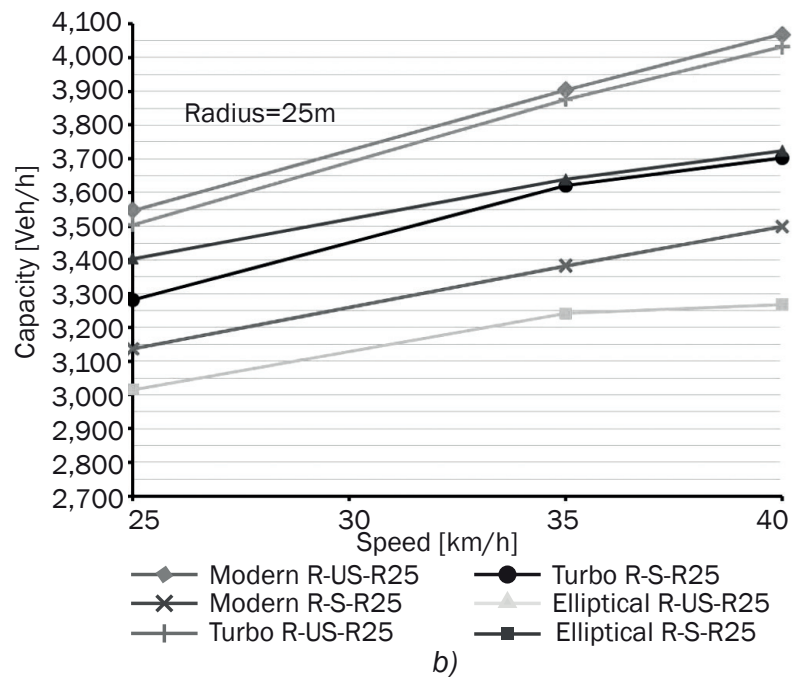

b)

Figure 7 - The effects of radius (a) and speed limit (b) on capacity in different types of two-lane roundabouts

Table 3 - Summary of the results observed for different two-lane roundabouts

\begin{tabular}{||l|c|c|c|c|c|c||}
\hline \multirow{2}{*}{} & \multicolumn{2}{|c|}{ Modern roundabout } & \multicolumn{2}{c|}{ Turbo roundabout } & \multicolumn{2}{c||}{ Elliptical roundabout } \\
\cline { 2 - 7 } & Unsignalized & Signalized & Unsignalized & Signalized & Unsignalized & Signalized \\
\hline \hline The effect of increasing the radius on delay & $+-/+$ & + & + & + \\
\hline Unsaturated flow & $-/+*$ & + & + & + & + \\
\hline Saturated flow & + & + & + & + & + \\
\hline The effect of increasing the speed limit on delay & + & + & + \\
\hline Unsaturated flow & + & + & + & + & + \\
\hline Saturated flow & + & + & + & + & + \\
\hline The effect of increasing the radius on capacity & - & + & + & + \\
\hline
\end{tabular}

* (-/+): first negative effect and then positive effect 


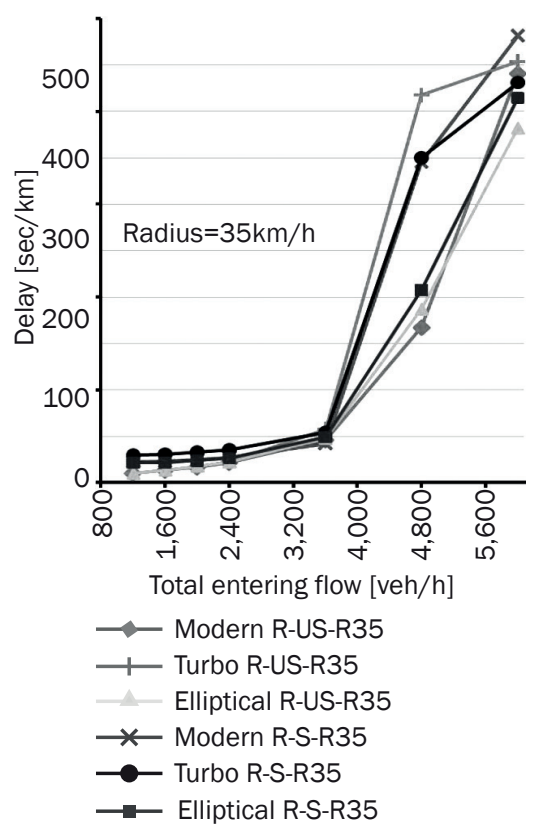

a) Radius of $35 \mathrm{~m}$

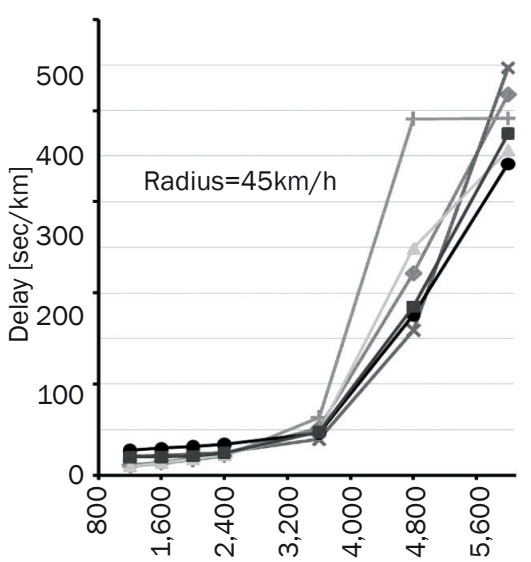

Total entering flow [veh/h]

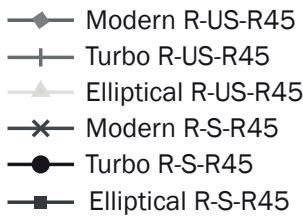

b) Radius of $45 \mathrm{~m}$

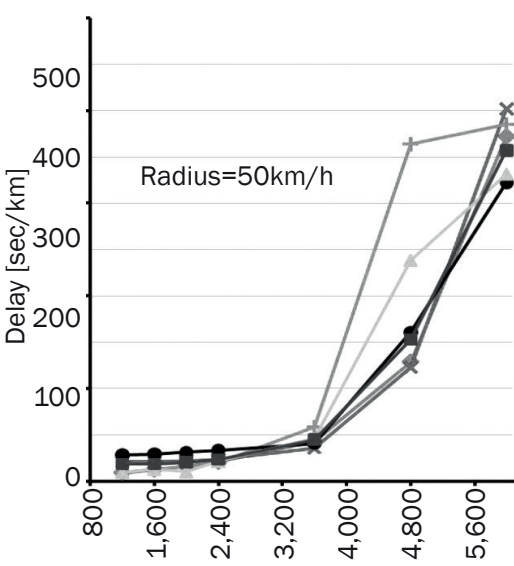

Total entering flow [veh/h]

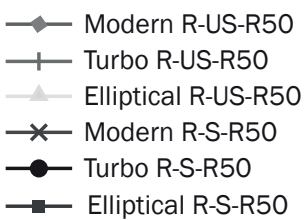

c) Radius of $50 \mathrm{~m}$

Figure 8 - The effect of radius variations on delay for a constant speed of $35 \mathrm{~km} / \mathrm{h}$ among different types of three-lane roundabouts

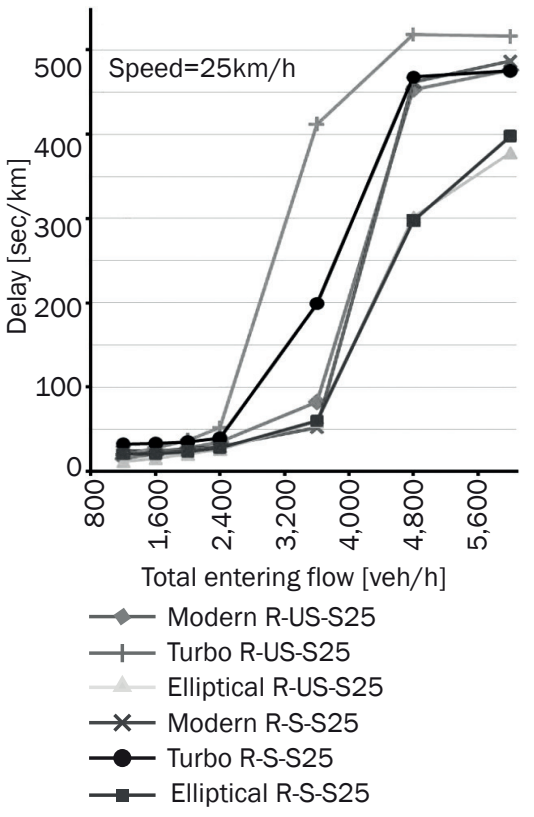

a) Speed of $25 \mathrm{~km} / \mathrm{h}$

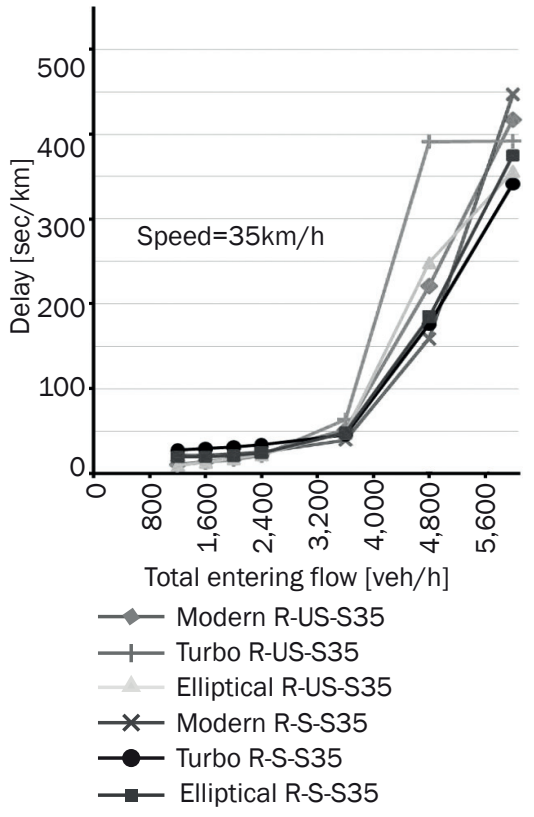

b) Speed of $35 \mathrm{~km} / \mathrm{h}$

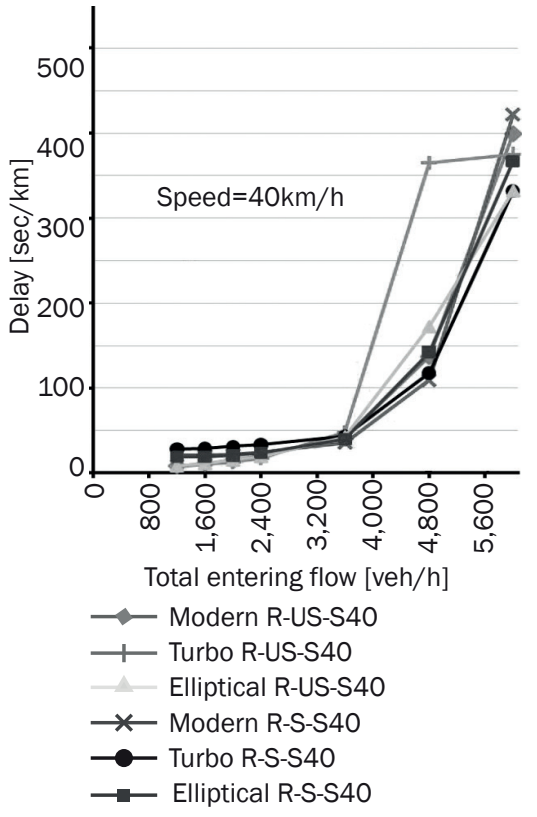

c) Speed of $40 \mathrm{~km} / \mathrm{h}$

Figure 9 - The effect of speed variations on delay for a constant radius of $45 \mathrm{~m}$ in case of different types of three-lane roundabouts

\subsection{Three-lane roundabouts}

Figures 8 and 9 represent the effects of radius and speed variations on delay, and the results of capacity are shown in Figure 10.

The effect of radius variations on delay for a constant speed of $35 \mathrm{~km} / \mathrm{h}$ is shown in Figure 8 . In the unsaturated flow, by increasing the radius of unsignalized modern and elliptical roundabouts the delay first increased and then decreased. For unsignalized turbo roundabout under unsaturated flow, an increase in radius caused a decrease of the delay. In the saturated flow, by increasing the radius, the delay was decreased in all roundabouts. Moreover, in the signalized roundabouts, the delay decreased in all flow conditions. As one can see in Figure 8, in unsignalized roundabouts, the modern roundabout had the lowest delay time under the unsaturated flow. However, 
the elliptical roundabout had the lowest delay time under the saturated flow. In signalized roundabouts, the elliptical roundabout had the lowest delay time under the unsaturated flow in the radius of 35 and $45 \mathrm{~m}$; however, in the radius of $50 \mathrm{~m}$, the modern roundabout performed better than the other roundabouts. In the saturated flow, the elliptical roundabout had the lowest delay time in the radius of $35 \mathrm{~m}$. However, in the radii of 45 and $50 \mathrm{~m}$, the turbo roundabout performed better than the other roundabouts.

The effect of speed limit variations on delay is shown in Figure 9. Under all flow conditions, with increasing the speed limit, the delay was decreased in all roundabouts. In unsignalized roundabouts under unsaturated flow, the elliptical roundabout had the lowest delay time at speed limit of $25 \mathrm{~km} / \mathrm{h}$. Meanwhile, for the speed limit of 35 and $40 \mathrm{~km} / \mathrm{h}$, the modern roundabout had the lowest delay time. In unsignalized roundabouts, the elliptical roundabout had the lowest delay time under the saturated flow. In signalized roundabouts under the unsaturated flow, the same behaviour was observed. Under the saturated flow, the elliptical roundabout had the lowest delay time at speed limit of $25 \mathrm{~km} / \mathrm{h}$. Meanwhile, for the speed limit of 35 and $40 \mathrm{~km} / \mathrm{h}$, the turbo roundabout had the lowest delay time.

The results of capacity are represented in Figure 10. The turbo roundabout in both unsignalized and signalized controls had the lowest capacity. Increasing of the central island radius of unsignalized roundabouts caused first a slight decrease of the capacity followed by an increase (Figure 10a). By increasing the central island radius, the capacity was increased in signalized turbo and modern roundabouts. With increasing the radius, the capacity of signalized elliptical roundabout showed almost no fluctuation. In addition, by increasing the speed limit, the capacity of all roundabouts was increased (Figure 10b). The capacity of signalized roundabouts was higher than of the unsignalized roundabouts. However, an increase in the speed limit caused unsignalized modern roundabout to perform better than the signalized modern roundabout. A summary of the results observed for different three-lane roundabouts is presented in Table 4.

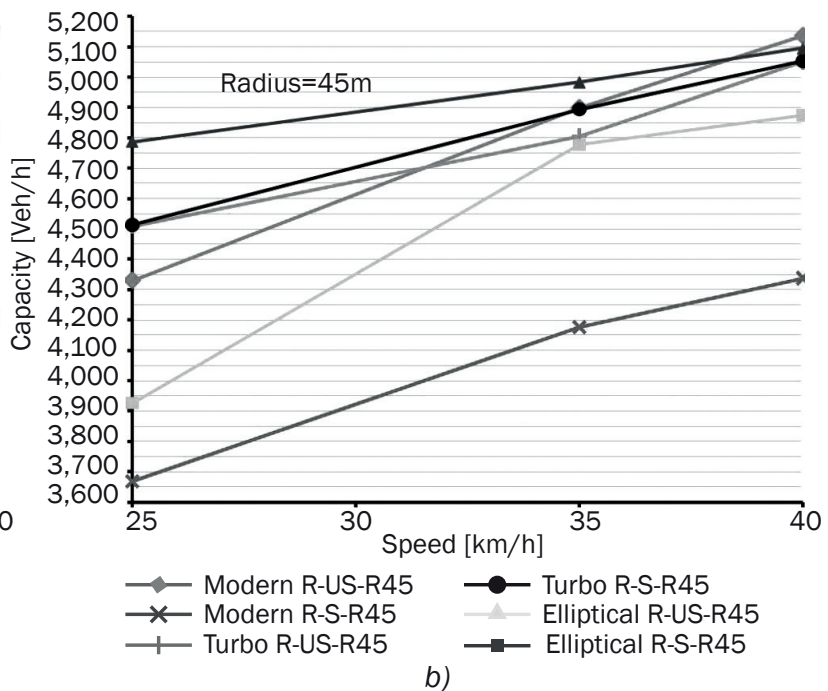

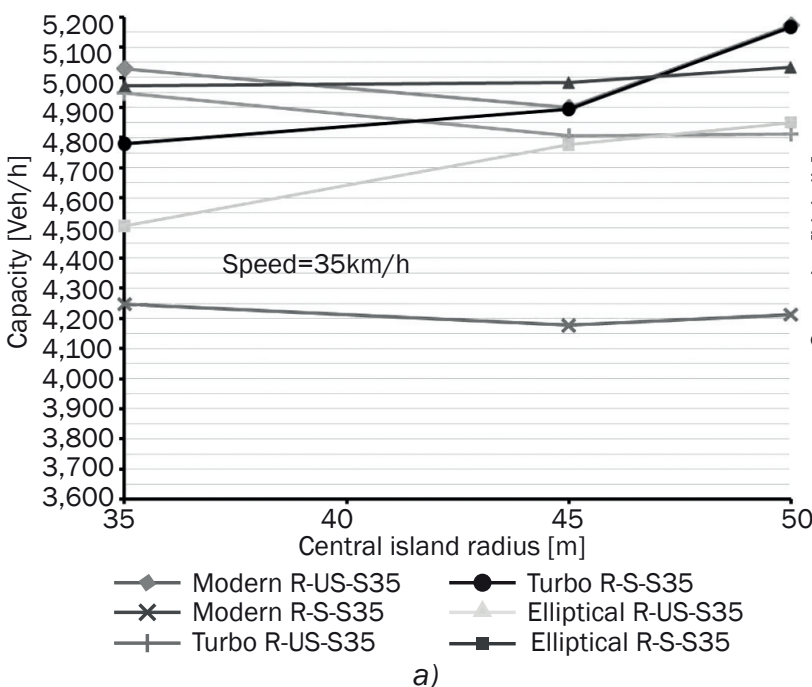

Figure 10 - The effects of radius (a) and speed limit (b) on capacity for different types of three-lane roundabouts

Table 4 - Summary of the results observed for different three-lane roundabouts

\begin{tabular}{|c|c|c|c|c|c|c|}
\hline & \multicolumn{2}{|c|}{ Modern roundabout } & \multicolumn{2}{|c|}{ Turbo roundabout } & \multicolumn{2}{|c|}{ Elliptical roundabout } \\
\hline & Unsignalized & Signalized & Unsignalized & Signalized & Unsignalized & Signalized \\
\hline \multicolumn{7}{|c|}{ The effect of increasing the radius on delay } \\
\hline Unsaturated flow & $-/+$ & + & + & + & $-/+$ & + \\
\hline Saturated flow & + & + & + & + & + & + \\
\hline \multicolumn{7}{|c|}{ The effect of increasing the speed limit on delay } \\
\hline Unsaturated flow & + & + & + & + & + & + \\
\hline Saturated flow & + & + & + & + & + & + \\
\hline \multicolumn{6}{|c|}{ The effect of increasing the radius on capacity } & + \\
\hline & $-1+$ & + & $-1+$ & + & $-1+$ & $\mathrm{NE}^{*}$ \\
\hline \multicolumn{7}{|c|}{ The effect of increasing the speed limit on capacity } \\
\hline & + & + & + & + & + & + \\
\hline
\end{tabular}

* NE: no effect 


\section{CONCLUSION}

The purpose of this study was to investigate the behaviour of elliptical roundabouts in unsignalized and signalized controls. Also, the effects of increasing the central island radius and speed limit on the delay and capacity were evaluated. Moreover, the elliptical roundabout was compared with the turbo and modern roundabouts considering the unsignalized and signalized controls.

The effects of increasing the central island radius in unsignalized and signalized controls under all flow conditions are as follows: by increasing the central island radius, the positive impacts on delay and capacity were observed in signalized roundabouts. Thus, the delay time was decreased and the capacity was increased in these roundabouts. However, the negative impacts on delay and capacity were observed in unsignalized roundabouts. By increasing the number of lanes, the negative impacts on delay and capacity were reduced. In addition, the behaviour of elliptical roundabouts was similar to modern roundabouts. However, the major impact of increasing the central island radius was observed in modern roundabouts.

The effects of increasing the speed limit in unsignalized and signalized controls under all flow conditions are as follows: the positive impact on all the roundabouts performances was observed with increasing the speed limit. The delay time was decreased and the capacity was increased. By increasing the speed limit, the delay reduction on signalized roundabouts was more significant than on unsignalized roundabouts. However, an increase in the capacity of unsignalized roundabouts was more significant than on signalized roundabouts. An increase in the speed limit along with increasing the number of lanes can be more effective in delay times.

The comparison of all roundabouts in terms of delay and capacity are as follows: Modern roundabouts had the lowest delay time in unsignalized and signalized controls under unsaturated flow conditions. However, by increasing the number of lanes, an elliptical roundabout had the lowest delay time. In unsignalized and signalized controls under saturated flow conditions, the elliptical roundabout had the best performance in delay. The behaviour of unsignalized turbo roundabouts in three-lane roundabouts under unsaturated flow was similar to unsignalized elliptical roundabouts. In other situations, turbo roundabouts had the largest delay time.

In unsignalized roundabouts, a modern roundabout had the highest capacity. Also, the modern roundabout had the highest capacity in single lane signalized roundabouts. However, by increasing the number of lanes, a signalized elliptical roundabout had the highest capacity. In the unsignalized and signalized control, a turbo roundabout had the lowest capacity.

\section{REFERENCES}

[1] Chang I, Ahn SY, Hahn JS. Analysis of delay reduction effects on modern roundabouts according to the entry traffic volume. KSCE Journal of Civil Engineering. 2013;17(7):1782-1787.

[2] Fortuijn L. Turbo roundabouts: design principles and safety performance. Transportation Research Record. 2009;2096:16-24.

[3] Mehmood A, Easa SM. Optimizing geometric design of roundabouts: multi-objective analysis. Canadian Journal of Civil Engineering. 2006;33(1):29-40.

[4] Easa SM, Mehmood A. Optimizing geometric design of single-lane roundabouts: consistency analysis. Canadian Journal of Civil Engineering. 2004;31(6):10241038.

[5] Mauro R, Cattani M. Functional and economic evaluations for choosing road intersection layout. PROMET - Traffic\&Transportation. 2012;24(5):441-448.

[6] Tollazzi T, Giovanni T, Guerrieri M, Campisi T. Environmental, functional and economic criteria for comparing "target roundabouts" with one- or two-level roundabout intersections. Transportation Research Part D: Transport and Environment. 2015;34:330-344.

[7] Zhang L, Du W, Liu S, Zhang S. Dynamic vehicular delay analysis between a roundabout and a pre-timed traffic signal. In Eighth International Conference of Chinese Logistics and Transportation Professionals (ICCLTP); 2009; Chengdu, China: American Society of Civil Engineers. p. 3982-3988.

[8] Gagnon C, Sadek A, Touchette A, Smith M. Calibration potential of common analytical and microsimulation roundabout models: New England case study. Transportation Research Record. 2009;2071:77-86.

[9] Qu X, Ren L, Wang S, Oh E. Estimation of entry capacity for single-lane modern roundabouts: case study in Queensland, Australia. Journal of Transportation Engineering. 2014 July;140(7).

[10] Sisiopiku VP, Oh HU. Evaluation of roundabout performance using SIDRA. Journal of Transportation Engineering. 2001 March/April;127(2):143-150.

[11] Al-Madani HMN. Capacity of large dual and triple-lanes roundabouts during heavy demand conditions. Arabian Journal for Science and Engineering. 2013 March;38(3):491-505.

[12] Yap YH, Gibson HM, Waterson BJ. An international review of roundabout capacity modelling. Transport Reviews. 2013;33(5):593-616.

[13] Kim S, Choi J. Safety analysis of roundabout designs based on geometric and speed characteristics. KSCE Journal of Civil Engineering. 2013;17(6):1446-1454.

[14] Tracz M, Chodur J. Performance and Safety Roundabouts with Traffic Signals. Procedia - Social and Behavioral Sciences. 2012;53:789-800.

[15] Bai Y, Xue K, Wang T. Association of signal-controlled method at roundabout and capacity. In Ninth International Conference of Chinese Transportation Professionals (ICCTP); 2009; Harbin, China: American Society of Civil Engineers. p. 1-12.

[16] Maher M. The optimization of signal settings on a signalized roundabout using the cross-entropy method. Computer-Aided Civil and Infrastructure Engineering. 2008;23(2):76-85. 
[17] Silva AB, Vasconcelos L, Santos S. Moving from conventional roundabouts to turbo-roundabouts. Procedia - Social and Behavioral Sciences. 2014;111:137-146.

[18] Mauro R, Branco F. Comparative analysis of compact multilane roundabouts and turbo-roundabouts. Journal of Transportation Engineering. 2010;136(4):316322.

[19] Corriere F, Guerrieri M. Performance Analysis of Basic Turbo-Roundabouts in Urban Context. Procedia - Social and Behavioral Sciences. 2012;53:622-632.

[20] Engelsman JC, Uken M. Turbo roundabouts as an alternative to two lane roundabouts. In 26th Annual Southern African Transport Conference 2007; 2007; Pretoria, South Africa. p. 581-589.
[21] Giuffrè O, Grana A, Marino S. Turbo-roundabouts vs roundabouts performance level. Procedia - Social and Behavioral Sciences. 2012;53:590-600.

[22] Hoek RM. Signalized turbo roundabouts: a study into the applicability of traffic signals on turbo roundabouts. Master thesis. Civil Engineering and Geosciences, Transport \& Planning; 2013.

[23] Tollazzi T, Renčelj M, Turnšek S. New type of roundabout: roundabout with "depressed" lanes for right turning - "flower roundabout". Promet - Traffic \& Transportation. 2011;23(5):353-358.

[24] Robinson, B W. and Rodegerdts, L. Roundabouts: an informational guide, Report FHWA-RD-00-067, Federal Highway Administration, Washington D.C., USA. 2000. 